\title{
$\mathfrak{J} \mathfrak{n} \mathfrak{b} \mathfrak{a} \mathfrak{l}$ t.
}

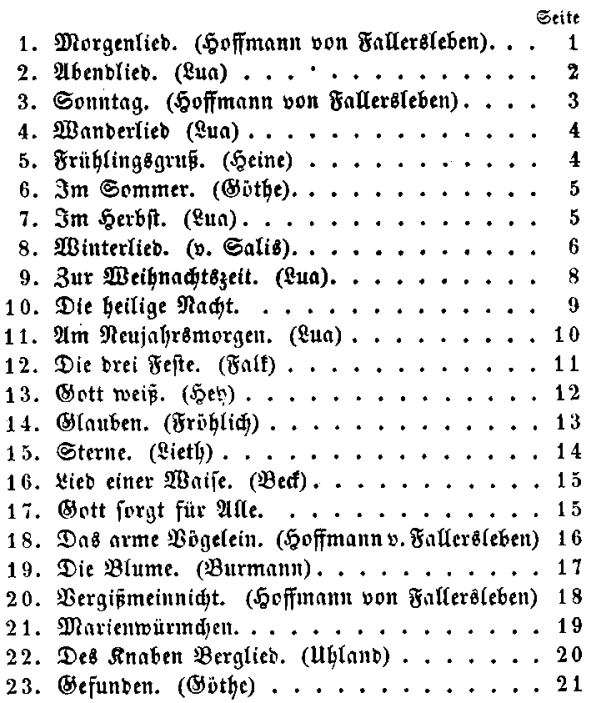




\section{- IV of}

Eeite

24. Shithicl. ................22

25. Die Savclle. (llblant) . . . . . . 23

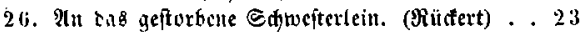

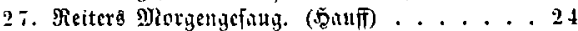

24. Ter gute famerist. (1tblant) . . . . . 25

29. (Ftins. (Iheremint) ........... 26

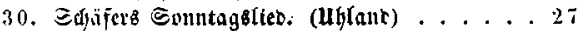

31. Der reiffife fitrft. (Rerner) ....... 29

32. Räthjel. . . . . . . . . . . 29

33. Getübde. (Minsmann) . . . . . . . . . 2!

34. Mein Baterfant. (

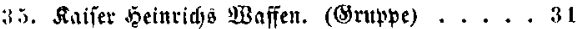

36. Barbaroffa. (Müutert) . . . . . . . . 33

3.. Jung छiegfrieb. (Lhland) . . . . . . 35

39. Rütbjel. ............. 36

39. Edjukenfier. (Equifer) ........ 37

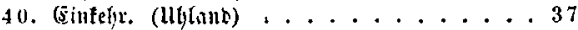

41. Finderlico yon rat grünen Eommerovigelı.

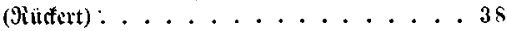

42. Eeemargen. (Eetiau) .........40

43. Sternhelfe Marft. (Mahlmann) . . . . 12

44. Dic HeberfaGrt. (atglant) ........43

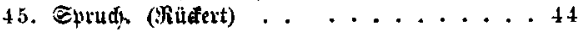

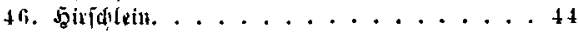

47. Tic Rudwe (llylund) ......... 45

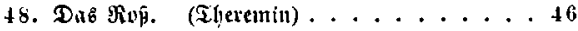

49. Madtliet. (\$sthe) .......... 47

50. Das Jetter. (§thiller) . . . . . . . . 47

51. Spritdpurt. ...........50

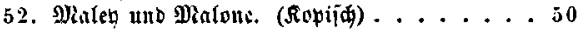

53. Gleid und geteid. (\$sthe) ...... 53

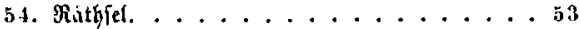

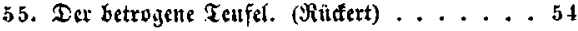




\section{$30 \quad 1 \quad 05$}

Ecle 56. Der Jumfer unb jein Rod. (Pjej̄el) . . . . 55

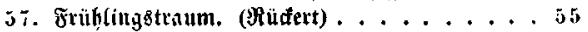

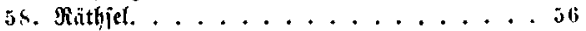
59. Wreis ter Taute. (ficrner) ....... 57 60. Bein Pltfitehn. (Putufert) ........ 5s 61. Nurke teine jungen Tage. (\$öthe) ..... 5s 62. Gegenribs. ............. 5! 63. Beim \$ingleinipiel. . . . . . . . 60 64. Die Beis, ter's zu nubl ift. . . . . . . bu

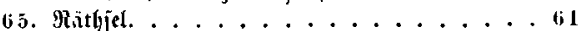

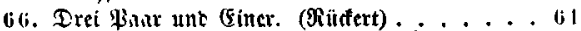
67. Der redte Barbier. ((5humiffo) . . . . 62 65. Sprud. (Stutfert) ..........65

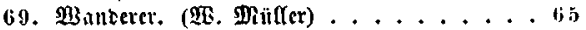

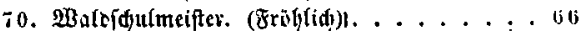
71. Die Eqlange. (Ridjtwer) ........ . . .

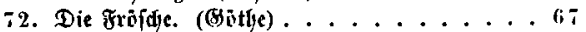

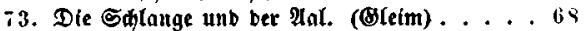

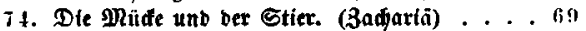
75. Stordf unb gribide. (\&ua) . . . . . . . 6!

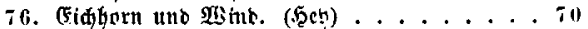

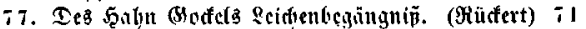

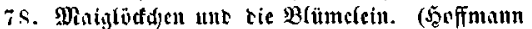
vơ GaUlerố(eben) . . . . . . . . 73

79. Rebenshortc. (gröhlidj) . . . . . . it

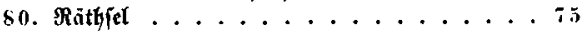

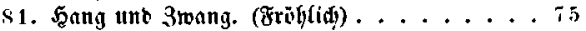

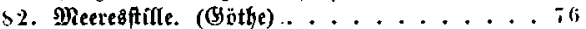

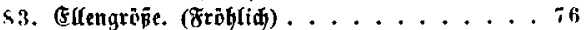

4. Der Shengit und bie \$eBpe. (S)Leim) . . . . it

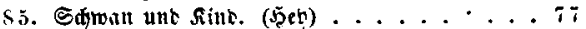

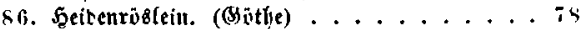

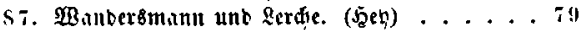


88. Der Brinde und ber Rahme, (Seflert) Eeile 89. Da fdilimnite Thier. (Refing) ......81

90. Der weipe Sirid. (llblanb) .......81

91. Morgengeipridje. (\&ua) ........ 82

92. Dns Sdwet. (llbland) ........ 83

93. Der (5rf́ñuig. (\$ithe) ........ 84

94. Stiñudjen. (uthlanb) ......... 85

95. Dre Ruten ber Steine. (Rofegarten) ....86

96. WBoftthutt. ((STaubiub) ........88

97. Meifelieb. (n. (Eidjenborff) ........88

9s. Eprud. (\&un) ............89

99. Die Putteripradje. (v. Edjententorf) . . . 90

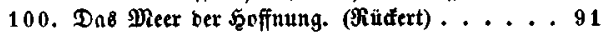

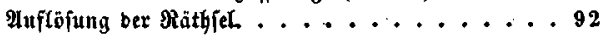

Biographifife Motizen. ........... 3 